\title{
Fatty acid methyl esters yield and phorbol esters degradation during transesterification of Jatropha curcas oil by alkaline, acid and enzyme catalyzed method
}

\author{
Koji Tosa ${ }^{1, *}$ and Tomoki Ishizuka ${ }^{2}$ \\ ${ }^{1}$ Kanazawa Institute of Technology, 7-1 Ohgigaoka, Nonoichi, Ishikawa 921-8501, Japan \\ 2 Nishihara Neo Co., Ltd, 2-11-5 Shibaura, Minato, Tokyo 108-0023, Japan
}

\begin{abstract}
Jatropha curcas has recently been the focus of intense research as a raw material of biomass fuel. However, the carcinogenesis promoter action of the phorbol esters in the Jatropha raises concerns for health and environmental risk. The purpose of the present study is to determine the relationship between the fatty acid methyl esters yield and the phorbol esters degradation ratio during the transesterification of the Jatropha oil by alkaline, acid and enzyme catalyzed method, respectively. The phorbol esters in Jatropha oil were degraded during the transesterification of the Jatropha curcas oil by alkaline and acid catalyzed methanol methods. The degradation ratio was significantly correlated with the fatty acid methyl esters yields in alkaline catalyzed transesterification. The results obtained in this study suggest that the health and environmental risk of the phorbol esters in a Jatropha BDF can be significantly reduced by a complete transesterification of the crude oil by controlling the transesterification condition appropriately.
\end{abstract}

\section{Introduction}

We human beings have been consuming large amounts of fossil fuels, including oil, coal and natural gas. Therefore, development of new renewable energies with low environmental load has been required in recent years. From these, there has been a growing interest in biodiesel fuel (BDF) which is a promising type of biomass fuels [1]. $\mathrm{BDF}$ is a diesel fuel that has been synthesized from animal and plant lipids. Most BDF is composed mainly of fatty acid methyl esters. BDF is a clean fuel compared to fossil fuels because it does not discharge the carbon dioxide from the concept of carbon neutrality. However, if rapeseed, foods like soybean and palm oil are used as a raw material for $\mathrm{BDF}$, there is a risk of competing with food supply.

Jatropha curcas has recently been the focus of intense research as a raw material of biomass fuel. Jatropha curcas can grow almost anywhere, even on gravelly, sandy and saline soils where food crops cannot grow [2]. However, the carcinogenesis promoter action of the phorbol esters contained in the Jatropha curcas oil raises concerns for health and environmental risk from the phorbol esters [3]; these concerns inhibit the promotion of the Jatropha curcas as a fuel. The purpose of the present study is to determine

\footnotetext{
* e-mail: tosa@kanazawa-it.ac.jp
}

the relationship between the fatty acid methyl esters yield and the phorbol esters degradation ratio during the transesterification of the Jatropha curcas oil produced by alkaline, acid and enzyme catalyzed method.

\section{Materials and methods}

\subsection{Deacidification}

Degummed Jatropha oil was purchased from Okinawa Biodiesel Co., Ltd. Free fatty acids in degummed Jatropha oil was removed by adding proper weight of sodium hydroxide. Excess sodium hydroxide in treated oil was neutralized by addition of citric acid and the oil was washed by hot water. Deacidified Jatropha oil was dried in a vacuum desiccator. Acid value of oil was determined according to JIS K 0070.

\subsection{Homogeneous alkaline catalyzed transesterification}

$10 \mathrm{~g}$ of deacidified Jatropha curcas oil and $2.21 \mathrm{~g}$ of methanol with sodium hydroxide in Erlenmeyer flask was mixed at $60{ }^{\circ} \mathrm{C}$ in a water bath shaker. The reaction products were separated by centrifugation at $3000 \mathrm{rpm}$ for $10 \mathrm{~min}$. The upper layer was neutralized by addition of citric acid and separated by centrifugation at $3000 \mathrm{rpm}$ for $10 \mathrm{~min}$. The neutralized upper layer was washed by hot water and centrifugation at $3000 \mathrm{rpm}$ for $10 \mathrm{~min}$. The washed upper layer was dried in a vacuum desiccator. 
Table 1. Analytical gradient conditions.

\begin{tabular}{lcc}
\hline Time $(\min )$ & Acetonitrile $(\%)$ & Water $(\%)$ \\
\hline 0 & 40 & 60 \\
26 & 75 & 25 \\
$35-55$ & 100 & 0 \\
\hline
\end{tabular}

\subsection{Solid alkaline catalyzed transesterification}

The procedure of solid alkaline catalyzed transesterification was almost the same as homogeneous alkaline method except for that appropriate weight of solid calcium oxide was used for catalyst. Calcium oxide was dried in an oven before use.

\subsection{Acid catalyzed transesterification}

$5.0 \mathrm{~g}$ of degummed Jatropha oil (not deacidified), $1.10 \mathrm{~g}$ of methanol and $0.05-0.25 \mathrm{~g}$ of sulfuric acid was mixed at $60{ }^{\circ} \mathrm{C}$ in a water bath shaker for 1-3 h. The reaction products were separated by centrifugation at $3000 \mathrm{rpm}$ for $10 \mathrm{~min}$. The upper layer was heated again at $80{ }^{\circ} \mathrm{C}$ and methanol was evaporated. The sample was washed by water, separated by centrifugation and dried in a vacuum desiccator.

\subsection{Enzyme catalyzed transesterification}

Deacidified Jatropha oil, methanol, water and lipase FAP-15 (Amano Enzyme Inc.) in Erlenmeyer flask was mixed at $40{ }^{\circ} \mathrm{C}$ in a water bath shaker. The weight of methanol, oil, water and lipase was controlled for the purpose of experimental objectives. Methanol was added to the reacting mixture after $24 \mathrm{~h}$ and $48 \mathrm{~h}$, respectively. The reaction products were separated by centrifugation at $3000 \mathrm{rpm}$ for $15 \mathrm{~min}$ and the upper layer was dried in a vacuum desiccator.

\subsection{Determination of fatty acid methyl esters and phorbol esters}

The separated upper layer by centrifugation after transesterification is usually BDF. The concentrations of phorbol esters and fatty acid methyl esters in Jatropha oil and BDF were analyzed by high-performance liquid chromatography (Prominence UFLC, Shimadzu) [4,5]. $20 \mu \mathrm{L}$ of sample was loaded on a LiChrospher 100 RP-18 (5 $\mu \mathrm{m})$ LiChroCART 250-4 column (Merck-Millipore) and eluted from the column by acetonitrile gradient in water at constant flow rate of $1.3 \mathrm{~mL} / \mathrm{min}$. Phorbol esters and FAMEs were detected with a UV detector at the wavelength of 280 and $205 \mathrm{~nm}$, respectively. Column oven temperature was $45^{\circ} \mathrm{C}$. Analytic gradients were shown in Table 1.

\section{Results and discussion}

\subsection{Homogenous alkaline catalyzed transesterification}

Percent yield of FAME and phorbol esters concentrations in BDF after reaction for $2 \mathrm{~h}$ are shown in Figure 1. Percent yield of FAME was calculated by dividing actual yield by the mass of material Jatropha oil. FAME was not

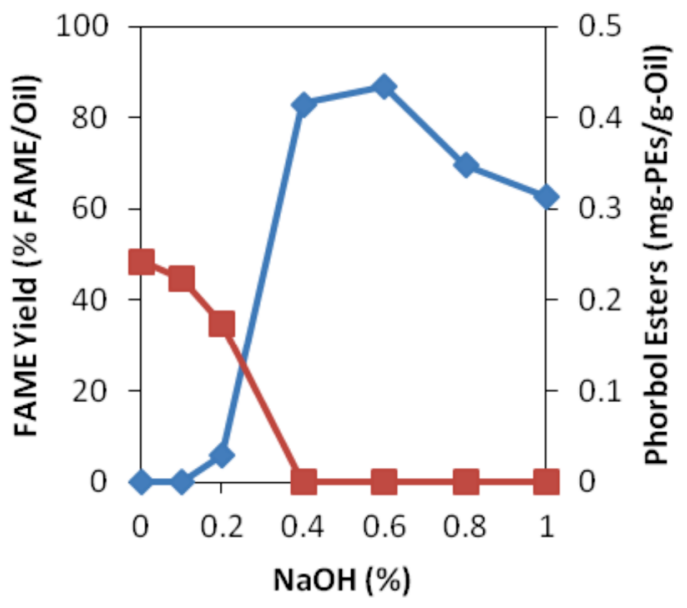

\section{$\leadsto$ FAME $\because$ Phorbolesters}

Fig. 1. Effect of $\mathrm{NaOH}$ on FAME yield and phorbol esters concentration in BDF after $2 \mathrm{~h}$ reaction in alkaline catalyzed transesterification.

produced in the reaction mixture containing $0.1 \%$ sodium hydroxide. Percent yield of FAME was about $7 \%$ in the reaction mixture with $0.2 \%$ sodium hydroxide. The maximum yield of FAME was $87 \%$ at a sodium hydroxide concentration of $0.6 \%$. The yield of FAME decreased at a sodium hydroxide concentration of over $0.8 \%$. If small amount of free fatty acids may residue in the raw material oil even after deacidification, the residual free fatty acids may react with sodium hydroxide. The acid value of deacidified oil in our study was $1.80 \mathrm{mg}-\mathrm{KOH} / \mathrm{g}$. Thus FAME was not produced at a lower sodium hydroxide concentration in this study. Excess addition of sodium hydroxide in transesterification causes saponification of lipids. The decrease of FAME yields with sodium hydroxide concentration of over $0.8 \%$ may be due to saponification by excess alkali. Phorbol esters in BDF were not detected at sodium hydroxide concentration of over $0.4 \%$. Not only lipids but also phorbol esters may be transesterified if mixed with alcohol. Transesterification of phorbol esters also occurred during transesterification of Jatropha oil in this study.

Time course of percent yield of FAME and phorbol esters concentrations in BDF at sodium hydroxide concentration of $0.5 \%$ are shown in Figure 2. Percent yield of FAME increased with reaction time and the maximum yield was gained for $0.5-1.0 \mathrm{~h}$. The concentration in phorbol esters in deacidified Jatropha oil was $0.24 \mathrm{mg} / \mathrm{g}$. Phorbol esters in BDF were not detected even after transesterification for $0.1 \mathrm{~h}$. Percent yield of FAME after $0.1 \mathrm{~h}$ was only $30 \%$. These results suggest that the reaction rate of phorbol esters are faster than those of oil and that transesterification may be efficient for degradation of phorbol esters.

The concentration of phorbol esters in Jatropha oil and BDF produced by potassium hydroxide catalyzed transesterification was 2.35 and $0.31 \mathrm{mg} / \mathrm{g}$, respectively [6]. The concentration of phorbol esters in Jatropha deacidified oil used in this study was $0.24 \mathrm{mg} / \mathrm{kg}$ and the value is much 


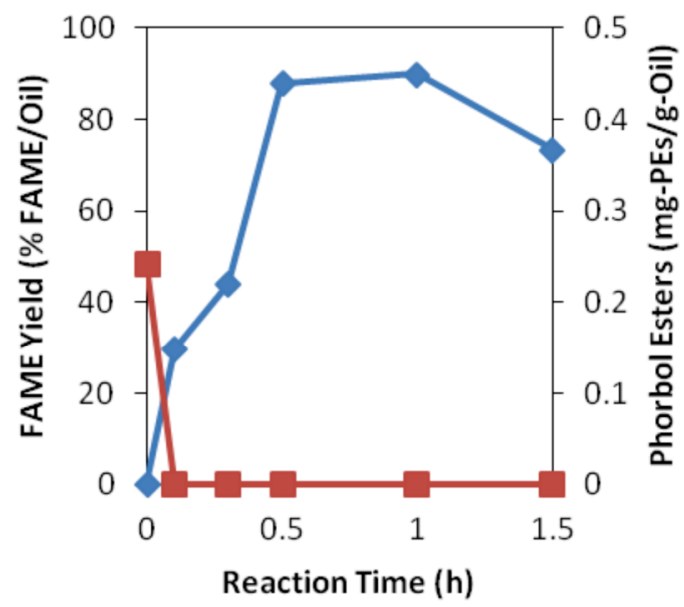

- FAME $\longrightarrow$ Phorbolesters

Fig. 2. Time course of FAME yield and phorbol esters in BDF in solid alkaline catalyzed transesterification $(\mathrm{NaOH} 0.5 \%)$.
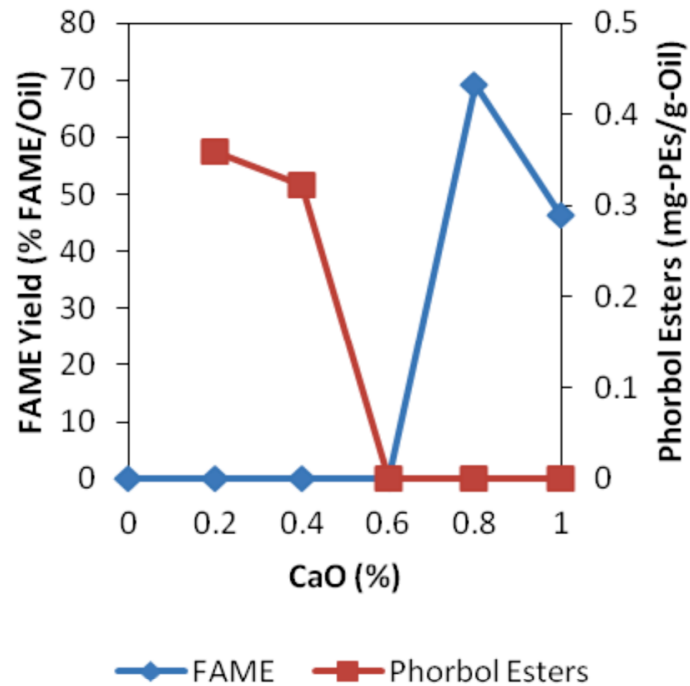

Fig. 3. Effect of $\mathrm{CaO}$ concentration on FAME yield and phorbol esters in the reaction products in solid alkaline catalyzed transesterification.

lower than that of the literature. The low concentration of phorbol esters in Jatropha oil was due to no detection of phorbol esters in BDF in our study. Prasad et al. found no phorbol esters in Jatropha biodiesel and the total conversion of Jatropha oil methyl ester after reaction was $96.05 \%$ [7]. Our results are accountable for the difference between the results of those two studies on phorbol esters in biodiesel fuel.

\subsection{Solid alkaline catalyzed transesterification}

Effect of solid catalyst (solid calcium oxide) concentration on FAME yield and phorbol esters concentration in BDF after transesterification of Jatropha curcas oil by alkaline solid catalyst method is shown in Figure 3. FAME was not produced when calcium oxide concentration was under $0.6 \%$. The more calcium oxide was added, the more phorbol
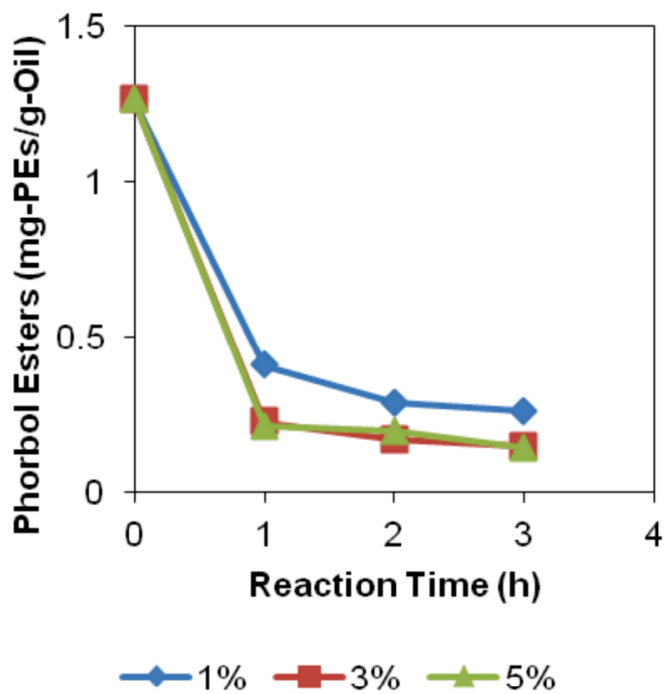

Fig. 4. Time course of phorbol esters in reaction products in acid catalyzed transesterification.

esters in BDF decreased. The phorbol esters in BDF decreased even when FAME was not produced. The result suggests that phorbol esters can more rapidly decrease than lipid reacts during transesterification of Jatropha curcas oil. Taufiq-Yap et al. reported transesterification of Jatropha crude oil to biodiesel on alkaline solid catalyst but not degradation of phorbol esters. This study presents that phorbol esters are degraded in transesterification of Jatropha oil on solid alkaline catalyst and the results is useful for safer Jatropha biodiesel production.

\subsection{Acid catalyzed transesterification}

Time course of phorbol esters in BDF after transesterification of Jatropha curcas oil by sulfuric acid catalyzed method is shown in Figure 4. The longer reaction time was extended, the more phorbol esters were degraded. The more catalyst was added, the more phorbol esters in BDF were degraded. However, the differences between the concentration of phorbol esters at $3 \%$ acid concentration and that at $5 \%$ acid concentration were not clear. Phorbol esters were detected in the BDF produced by the acid catalyzed method in this study. The concentration of phorbol esters in the Jatropha degummed oil used for this process was $1.3 \mathrm{mg} / \mathrm{g}$ and much higher than that of deacidified oil used in the alkaline methods in this study. The residence of phorbol esters in the BDF by acid catalyzed process is due to the high concentrations of phorbol esters in the material oil. The degradation ratio of phorbol esters by acid catalyzed transesterification was $89 \%$ in this study and the value is very close to $87 \%$ that was gained by alkaline catalyzed method [8].

\subsection{Enzyme catalyzed transesterification}

Phorbol esters in BDF produced by using lipase catalyzed method were not identified clearly from other substances by HPLC. The peaks of phorbol esters in HPLC chromatograms were covered with some peaks of other substances. Other methods for identification of phorbol esters from 


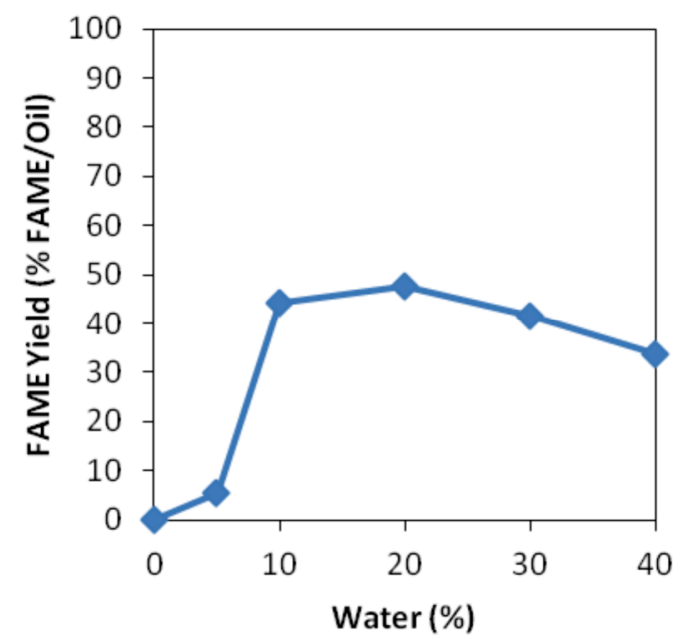

Fig. 5. Effect of water on FAME yield ( $0.28 \%$ lipase and $72 \mathrm{~h}$ reaction).

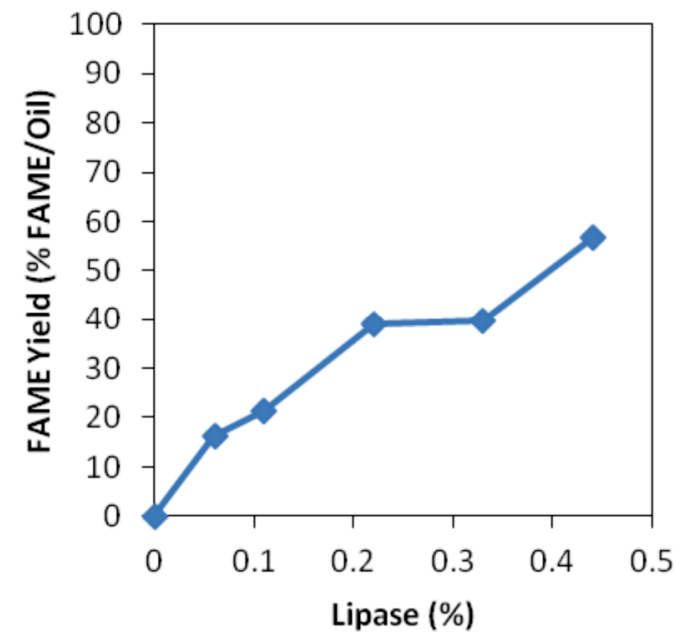

Fig. 6. Effect of lipase concentration on FAME yield $(72 \mathrm{~h}$ reaction).

other peaks should be developed. One solution is a combination of HPLC and mass spectrometry, namely LC-MS. Lipase is known to catalyze several kinds of reactions of lipids. More research is needed for determination of phorbol esters change in enzyme catalyzed transesterification process.

Effect of water content on FAME yield in lipase catalyzed transesterification is shown in Figure 5. The best water content for FAME yield was about from 10 to $20 \%$. Effect of lipase concentration on FAME yield in lipase catalyzed transesterification is shown in Figure 6. The more lipase concentration increased, the more FAME yield increased. The best lipase concentration might be more than $0.45 \%$, which is the highest concentration in this study.

Time course of FAME yield during lipase catalyzed transesterification process is shown in Figure 7. The highest FAME yield was gained after $80 \mathrm{~h}$ reaction and the yield was $56.2 \%$. A lipase catalyzed method needs more reaction time than alkaline catalyzed method. Moreover, the FAME yield by lipase catalyzed method is lower than that by homogenous alkaline method in this study.

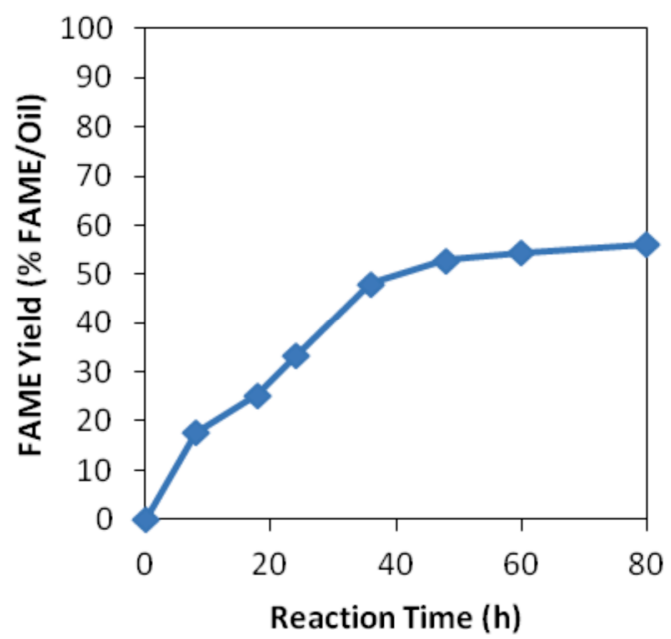

Fig. 7. Time course of FAME yield $(0.28 \%$ lipase and $72 \mathrm{~h}$ reaction).

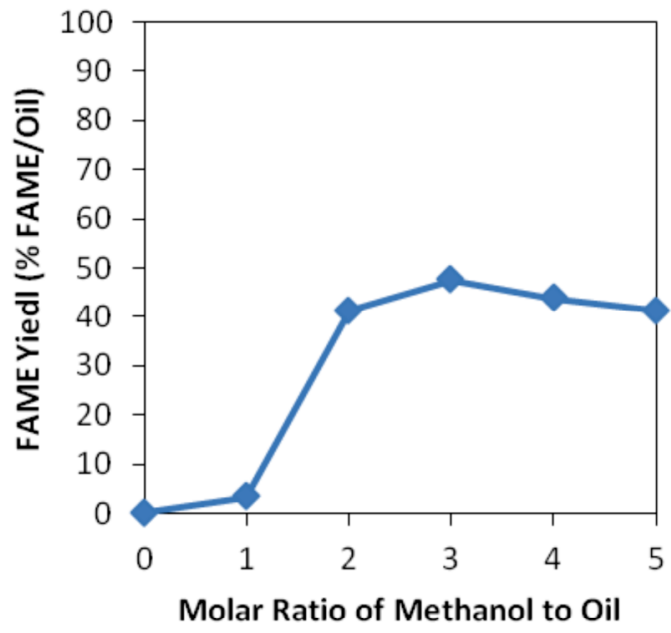

Fig. 8. Effect of molar ratio of methanol to oil on FAME yield $(0.28 \%$ lipase, $72 \mathrm{~h})$.

Effect of molar ratio of methanol to oil on FAME yield in lipase catalyzed transesterification is shown in Figure 8. The theoretical molar ratio for transesterification of lipid is 3 . In this study the best molar ratio was about 3 and agreed with the theoretical value. When the ratio was over the theoretical value, slight decrease in FAME yield was observed. The decrease of FAME yield is due to the toxicity of methanol to lipase [9]. We added methanol to the reaction mixture not in once but in three times for reducing the inhibition of lipase by methanol in this study, but the reduction is not complete.

\section{Conclusions}

The phorbol esters in Jatropha curcas oil were degraded during the transesterification of the Jatropha curcas oil by alkaline and acid catalyzed methanol methods. The degradation ratio of phorbol esters by alkaline catalyzed methods was significantly correlated with the fatty acid 
methyl esters yields. The results obtained in this study suggest that the health and environmental risk of the phorbol esters in a Jatropha curcas biodiesel fuel can be significantly reduced by a complete transesterification of the crude oil by controlling the transesterification condition appropriately.

This research was supported by JST/JICA, SATREPS.

\section{References}

1. D. Bajpai, V.K. Tyagi, Biodiesel: source, production, composition, properties and its benefits, J. Oleo Sci. 55, 487 (2006)

2. H. Makkar, K. Becker, Jatropha curcas, a promising crop for the generation of biodiesel and value-added coproducts, Eur. J. Lipid Sci. Technol. 111, 773 (2009)

3. M. Hirota, M. Sutajit, H. Suguri, Y. Endo, K. Shudo, V. Wongchai, E. Hecker, H. Fujiki, A new tumor promoter from the seed oil of Jatropha curcas L., an intramolecular diester of 12-deoxy-16-hydroxyphorbol, Canc. Res. 48, 5800 (1988)
4. H. Makkar, J. Maes, W.M. Greyt, K. Becker, Removal and degradation of phorbol esters during pretreatment and transesterification of Jatropha curcas oil, J. Am. Oil Chem. Soc. 86, 173 (2008)

5. M.S. Carvalho, M.A. Mendonca, D. Pinho, I.S. Resck, P. Suarez, Chromatographic analyses of fatty acid methyl esters by HPLC-UV and GC-FID, J. Braz. Chem. Soc. 23, 763 (2012)

6. M. Iwata, H. Furutani, Risk management of Jatropha oil and these BDF (especially phorbol esters which are important toxic substances), Proceedings of Internal Combustion Engine Symposium 21, 479 (2010)

7. L. Prasad, S. Pradhan, L.M. Das, S.N. Naik, Experimental assessment of toxic phorbol ester in oil, biodiesel and seed cake of Jatropha curcas and use of biodiesel in diesel engine, Appl. Energy 93, 245 (2012)

8. Y.H. Taufiq-Yap, S.H. Toe, U. Rashid, A. Islam, M.Z. Husseien, K.T. Lea, Transesterification of Jatropha curcas crude oil to biodiesel on calcium lanthanum mixed oxide catalyst: effect of stoichiometric composition, Energy Convers. Manage. 88, 1290 (2014)

9. T. Hata, M. Shimada, J. Toida, Experimental study of the new biocatalyst method for biodiesel-fuel based on the lipase production fungus, J. Jpn. Soc. Civil Eng. Ser. G: Environ. Res. 67, 250 (2011)

Cite this article as: Koji Tosa, Tomoki Ishizuka, Fatty acid methyl esters yield and phorbol esters degradation during transesterification of Jatropha curcas oil by alkaline, acid and enzyme catalyzed method, Renew. Energy Environ. Sustain. 2, 1 (2017) 